\title{
¿Una grieta en la filosofía moral de Kant? (A propósito del imperativo categórico como mandato divino)
}

\author{
JOSÉ MANUEL PANEA MÁRQUEZ \\ Universidad de Sevilla
}

El problema del bien supremo en Kant desempeña un importante papel dentro de la justificación de su filosoffa moral. El formalismo kantiano, su versión del imperativo categórico como universalización de la conducta moral, parece insuficiente a la hora de afrontar no sólo el problema ético del discemimiento, sino tambićn el problema de la realizabilidad del proyecto ético, de su ejecución. La reformulación del imperativo categórico, a la manera (gleich als) de mandato divino, nos exige una reflexión sobre su génesis y alcance en el proyecto kantiano de una moral fundada sólo en la pura razón.

$$
* * *
$$

Justificar la propia vida, querer aquello que hacemos, y comprender el sentido de lo hecho, tal vez aquí se encierre el más profundo significado de la libertad. Porque estamos acostumbrados, quizás por deformación profesional, a vislumbrar los problemas filosóficos con la frialdad analítica y diseccionadora que igualmente empleariamos al desmontar un artilugio mecánico, seguramente habremos imaginado al filósofo de $\mathrm{Kö}$ nigsberg en su elaboratorio", puliendo conceptos, realizando mezclas cuidadosas, separando y distingujendo para ofrecernos un producto filosófico depurado. El formalismo kantiano, su rigorismo y escrupulosidad moral, del que tanto se ha hablado, tal vez ha tejido un 'velo de ignorancia' que, en su idealidad, ha ocultado el fondo, el verdadero artífi- ce de la alquimia filosófica: la nẹcesidad que tenemos de comprender -aunque sea mínimamente- aquello que somos y hacemos. Y Kant, como nosotros, también era humano; tras la sólida arquitectura conceptual con la que trazó su sistema filosófico, seguía estando el hombre, $y$, por tanto, esa imperiosa necesidad de justificar la propia vida. Y eso fue lo que escondía su afán de elaborar un proyecto ético coherente.

Pero si irrenunciable es la comprensión del sentido de lo que queremos y hacemos, igualmente lo será, para Kant, tanto la aspiración humana a la felicidad -independientemente de cuál sea su contenido-, cuanto la necesidad de conducirnos mediante fines. ${ }^{1} \mathrm{Y}$ Kant, nuevamente, sigue siendo un hombre $y$, por tanto, no puede renunciar a la felicidad ni a la exigencia de fines prácticos para la conducta. Claro que, en su pretensión de dar cumplimiento al imperativo de la Aufklärung de servirse de la propia razón, ${ }^{2}$ así como de atreverse a caminar y valerse por sí mismo, sin la ayuda de nadie, sin amuletos ni muletas, tampoco podía hacer depender el universo moral de una dama tan caprichosa, cambiante ${ }^{3}$ y seductora como la felicidad. A la vez que abrir la puerta a la felicidad en el terreno moral ${ }^{4}$ implicaba dejar pasar elementos empíricos heterónomos en la determinación del obrar, cuando lo que se pretende es, justamente, huir de toda heteronomia, ser uno mismo en el sentido de ser "racionalmente autónomos». Pero con este portazo, la felicidad no es expulsada del 
ámbito moral, antes al contrario, la felicidad y sus nupcias con la moralidad propician ese enlace perfecto entre el reino de la naturaleza y el reino de la libertad, enlace que Kant no duda en considerar como el bien supremo, y que será el objeto y meta final de la razón práctica pura, $y$, por tanto, el objeto último de toda conducta. ${ }^{5}$

Nunca exageraremos al destacar la importancia del bien supremo en la filosofia moral de Kant. En primer lugar, si aquél fuera sólo una quimera, toda esperanza utópica de lograr un progreso moral en la historia seria vana por imposible." Pero la idea del bien supremo no sólo colma una aspiración utópica de la humanidad en su conjunto, sino que también proporciona un punto de referencia de la unión de todos los fines, ${ }^{7}$ lo cual, a su vez, satisface la necesidad subjetiva de obrar con sentido, ${ }^{8}$ pues sin relación de fin la voluntad del hombre es incapaz de autodeterminarse."

Pero es a partir del reconocimiento de la importancia y de la necesidad de postular la aspiración a conquistar ese maximum de felicidad y moralidad, perfectamente enlazados, y que Kant llamará bien supremo, cuando el proyecto de una (filosofía) moral autónoma empieza a plantear serios problemas. $\mathrm{Y}$ Kant, por supuesto, es el primero en darse cuenta de que el sueño de una ínsula moral, en la que el sujeto conserva toda su autonomía no es tan fácilmente realizable. Kant conoce bien el corazón del hombre, conoce su inestabilidad y sabe que es imprevisible lo que hará. Por consiguiente Kant quiere garantizar al máximo la realizabilidad del imperativo categórico, sin el que no hay moralidad posible. El problema de fondo es, pues, sencillo y difícil a un tiempo; sencillo porque lo que debe hacerse ya lo sabemos: obrar lo más ajustadamente posible a lo que dicta el imperativo ca- tegórico; y dificil, porque se presenta como una tarea escabrosa para un corazón en el que existe una mezcla de bien y de mal. Por esta razón, Kant no dudará en llegar a la conclusión de que es necesario que la voluntad quiera como querria un ser moralmente irreprochable, o, como dirá el propio Kant: lograr el máximo bien posible, que es para mí el objeto ultimo de toda conducta, no será posible a menos que mi voluntad llegue a coincidir con la de un autor santo y bondadoso del mundo.to Expresado en otros términos, será necesario que nuestra voluntad adopte "el punto de vista" de un ser absolutamente bueno, porque, para no errar en la moralidad de nuestra acción, no bastará que podarnos universalizar nuestra voluntad, ni que desliguemos nuestra acción de toda instrumentalización de nuestra persona o de la de cualquier hombre. En efecto, el imperativo categórico nos dicta la pauta de cómo debemos obrar. Pero no sólo es importante saber cómo obrar, sino ejecutar la acción, y más aún, no errar en el móvil -pues sólo de aquí puede proceder la depravación de la voluntad o del corazón-, "1 y para ello es preciso que nuestra voluniad, en un esfuerzo de imaginación ética, sea capaz de querer como si fuéramos Dios; querer como si lo ordenado por nuestra propia razón fuera ordenado por un ser santo y bondadoso del mundo. $\mathrm{Y}$, en este contexto es, precisamente, en el que surge la reformulación o la reconsideración del imperativo categónico como mandato divino. ${ }^{12}$ Pero, a nuestro juicio, el tratamiento del imperativo categónico como mandato divino persigue en Kant dos objetivos: por una parte, garantizar la moralidad de nuestras acciones, asemejando nuestra voluntad a la de un ser absolutamente bueno (así aparece en la Kritik der praktischen Vemunft ( $\mathrm{KpV}$ ) y en las Lecciones de Etica); por otra, garantizar la realizabilidad o ejecutabili- 
dad del imperativo moral (Ak., vol. VI, pp. 438-440; Opus postumum, p. 591).

Así pues, Kant, que quiere curarse en salud, ha delimitado tajantemente el plano del discemimiento y el de la ejecución,,$^{13}$ distinguiendo lo que es pauta y lo que es móvil. Pero tal distinción, que teóricamente no puede ser más nútida, en la práctica concreta, en la vida real, que es donde realmente nos enfrentamos ante la necesidad de tomar decisiones en un sentido o en otro, tal jorismós no resulta tan claro, pues el propio Kant está admitiendo, de algún modo, que el limite entre la pauta-discernimiento y el móvil-ejecución no es un territorio perfectamente cercado, sino más bien resbaladizo, en lo que atañe al papel que en tales ámbitos jugaría un Dios postulado sólo a efectos prácticos, con independencia de su existencia. En efecto, el imperativo categórico como mandato divino presenta también ese rostro de Jano que mira en dos direcciones: por una parte viene a completar o a rellenar el formalismo de una voluntad universalizable, al ponemos en la tesitura de cuestionarnos si tal conducta sería querida por una voluntad absolutamente buena y bondadosa ${ }^{14}$ (mandato divino). Pero, por otra parte, nos obliga a acatar la ley moral como inviolable (mandato divino).$^{15}$

Por todo ello, aun cuando Kant nos advierta de que Dios, cuya necesidad práctica en la filosofía moral kantiana entendemos ahora perfectamente, es un postulado de la razón pura práctica; aun cuando Kant, con una insistencia que se nos muestra ahora diáfana, se esfuerza una y otra vez en subrayar que Dios no es una substancia exterior a mí (sino que se trata de un Deus in nobis, ${ }^{16}$ cuya realidad es sólo práctica), aun siendo todo ello asi, Kant ha iniciado un camino sin retorno, en cuyo despliegue acabará reconociendo, coherentemente con sus propias tesis, que la Moral se abre ineludiblemente a la Religión. ${ }^{17}$ La Moral -a través de la necesidad de un concepto como el del bien supremo- termina engendrando a aquélla; ${ }^{18}$ la Religión no es el fundamento de la Moral, sino al revés, pero esto no debe ser, a nuestro juicio, ningún consuelo para una Moral que aspira a la autonomía y que, sin embargo, después de crear-postular a Dios no puede prescindir de él, no ya sólo en el terreno del discernimiento (aunque Kant no lo aceptaría o se resistiría a ello), sino también en el plano de la ejecución. Porque resulta que aunque Dios no sea más que una ficción práctica, si el imperativo categónico a la manera de (gleich als) mandato divino cobra un papel tan importante $-y$, extrañamente tan silenciado- en el proyecto ético kantiano, me atrevería a sugerir si no es ésta una grieta necesaria y profunda, en su sistema moral, consecuencia, sin duda, de la coherencia y radicalidad con la que ha desplegado su pensamiento, evidenciando los problemas - y esta sería la grandeza de Kant - con los que acaba topándose la razón pura práctica cuando al querer valerse sólo de sí misma, fiel al lema de la Aufklänung, termina renunciando a todo lo que no es ella; es decir, a todo, salvo a sus ficciones.

\section{NOTAS}

1. Edición de la Akademia (Ak), vol. Vt, p, 4.

2. Ak., VIII, 35.

3. En tanto ideal de la imaginación. Cf. Ak., $\mathrm{V}$, 418.

4. Por lo que respecta a su fundamentacion, pues, como el propio Kant advicrte, en determinadas ocasiones, hasta puede ser un deber cuidar de la propia felicidad, precisamente para no poner en peligro el deber. Cf. Ak, V, 93.

5. Ak, V, 129. 
6. Sobre el concepto de bien supnemo y su importancia en la filosofía kantiana de la historia, cf. R Rodríguez Aramayo: «El bien supremo y sus postulados (Del formalismo ético a la fe racionalln, Revista de Filosofia (Madrid), 7, 87-118 (1984), 112-115

7. Ak., VI, 5.

8. O, como dira Kant, a[...] esta idea (considerada practicamente) no es vacla, pues pone remedio a nuestra natural necesidad de pensar en algún fin úlimo que pueda ser justificado por la Razón para todo nuestro hacer y dejar tomado en su todo, necesidad que de otro modo sería un obstáculo para la decision moral\%. Cf. I. Kant: La Religión dentro de los limites de la mera Razón, F. Martínez Marzoa (ed.), Madrid, Alianza Editorial, p. 21 (el subrayado es nuestro); $A k$, VI, 5 .

9. Ak., Vi, 4 .

10. Ak, V, 129.

11. Cf. I.Kant: Lecciones de Etica, R. Rodriguez Aramayo y $\mathrm{C}$, Roldán Panadero (eds.), Barcelona, Grijalbo/Critica, 1988, p. 84; Ak., XXVII.1, 279.

12. La idea la encontramos ya apuntada en las Lecciones de Ética, cuando escribe: «Una acción que tiene lugar conforme a la moralidad es la mayor coincidencia con la voluntad divina. De este modo consideramos a Díos no como un legislador pragmático, sino como un legislador moral». 1. Kant, ibid, p. 91, Ak, XXVII.1., 284. De un modo más explicito lo encontramos en Ak, V, 129; Ak, VI, 440, 487. Pero donde la formulación del imperativo categórico corno mandato divino adquiere verdadera intensidad es en el Opus postumum, un imperativo que, pese a la ficción práctica que incorpora , pues el agente moral se pone en el lugar de Dios, no deja de ser un imperativo racional, Cf. I. Kant: Transición de los principios metafisicos de la ctencia natural a la fisica (Opus postumum), F. Duque (ed), Madrid, Editora Nacional, 1983, p. 596; Ak, XXII, 56. En una de sus múltiples referencias que en esta obra encontramos, nos dice Kant: “El concepto $\rightarrow$ más bien la ideade Dios es el pensamiento de un ser ante el cual todos los deberes humanos son validos al mismo tiempo como mandatos suyos", ibid., p. 598; Ak, XXII, 58.

13. Cf. Lecciones de Etica, p. 75, Ak, XXVII.1, 275 y también el artículo de R. Rodríguez Aramayo: "La presencia de la "Crítica de la razón práctica" en las Lecciones de Etica de Kant", Ago ra (Santiago de Compostela), 7, 145-158 (1988), $155-157$.

14. Vendria, asi, a colaborar en esa introspección o vigilantia moralis de nuestros actos, para velar por la pureza moral. Ct. Lecciones..., op. cit., p. 165, Ak., XXVII.1, 348.

15. Un texto esclarecedor en extremo podria ser éste, y que leemos en su Opus postumum: aEl imperativo categónico representa todos los deberes del hombre como mandatos divinos, no historicamente; no como si hubiera alguna vez ordenado cientos mandatos a los hombres, sino tal como la razon -en virtud del poder supremo del imperativo categorico, como si se tratara de una persona divinapueda prescribirselos a si misma para someterse estrictamente a aquel.. Ibid., p. 591, Ak., XXII, 52. Cf. un poco más adelante, Ibid, p. 594, Ak. $\mathrm{XXII}, 53$.

16. Cf. Opus postumtim, p. 615, Ak., XXII, 130. Cabria establecer la hipotesis de que la insistencia de Kant en el $O p$. sobne el carácter inmanente de Dios tendria una clara concxión con la también rềterada insistencia en dichos escritos de considerar al imperativo categórico como mandato divino. Así, al inmanentizar a Dios en la razón práctica, tal reformulacion del imperativo categónico contrarrestaria toda posible sospecha de heteronomia. Para el tema de Dios en Kant, of. A Cortina: Dios en la filosofla trascendental de Kant, Salamanca, Universidad Pontificia, 1981.

17. Ak, VI, 6 .

18. Quisiera hacer una advertencia, para ahorrar malentendidos, que el imperativo categórico como mandato divino implica la adopción de un punto de ista monl y no la adopción de normas dictadas por un ser divino. La otra función que atribuimos a la adopeión de este punto de vista es el de considerarlo como un mandato de inexorable cumplimiento, como una limitacion, pues, del capricho (cf. Op., p. 604, Ak., XXII, 64). Pero en ningún modo hay que pensar que con tal reformulación del imperativo Kant nos este hablando de mandato de un ser superior (Dios), porque, por una parte, el Dios kantiano es inmanente a la razón práctica (ens rationis, se dice muy a propósito en Op., p. 612, Ak., XXII, 126), y, por otra parte, la aceptación de mandatos divinos como tales iría contra el dictado de la ley moral, segîn el cual, todo ser racional, en tanto fin en st. no puede ser utilizado solo como medio por nadie, ni siquiera por Dios. Cf. Ak. V, 131. 